\title{
Editorial
}

\section{Psiconeuroimunologia e a pesquisa em Enfermagem: descoberta, mudanças de paradigma e inovações metodológicas}

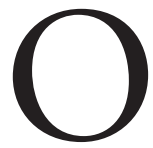

termo "Psiconeuroimunologia" (PNI) emergiu na década de 1970 com o trabalho de Robert Ader $^{(1)}$ e, a partir de então, difundiu-se como expressão para designar o campo da ciência que estuda de modo interdisciplinar a interação entre os processos psicológicos e as funçôes neurológica, endócrina e imunológica, e como essa interação influencia na saúde. Nas últimas décadas, um corpo crescente de pesquisas envolvendo neuroimunomodulação tem fornecido fortes evidências e novos insights que sustentam esse emergente campo da ciência, uma vez que uma variedade de estressores físicos e psicossociais-espirituais pode alterar a resposta imune através de vias psiconeuroimunoendócrinas. ${ }^{(2)}$

Segundo o framework da PNI, mediadores inflamatórios e outros mediadores imunes inatos podem sinalizar ao sistema nervoso central (SNC), estimular a produção de citocinas, alterar a função neuronal e desencadear o "sickness behavior" - "comportamento doentio" - como resposta adaptativa. (2,3) O termo sickness behavior foi cunhado em 1992 por Stephen Kent e colaboradores $^{(4)}$ para se referir ao conjunto de alteraçôes comportamentais que acompanhavam um grande número de processos patológicos que ocorriam aparentemente sem conexão. Os autores referiram-se, ainda, a alguns comportamentos modificados durante as doenças como, por exemplo, a ocorrência de alteraçóes no padrão do sono e a perda aparente do interesse por atividades cotidianas e positivas, como a busca por alimento, o contato social e o interesse sexual. ${ }^{(4)}$

Emergida da análise de processos infecciosos de várias origens, a história do comportamento doentio foi inicialmente marcada pelo estudo dos efeitos de produtos bacterianos sobre o comportamento. Dentre os produtos bacterianos analisados incluía-se o LPS, um lipopolissacarídeo de parede de bactérias gram-negativas. ${ }^{(5)}$ Desse ponto em diante, outras situaçóes patológicas como, por exemplo, o crescimento de neoplasias e doenças autoimunes, foram incluídas na gama de processos que podem gerar comportamento doentio. ${ }^{(6)}$

De modo bastante semelhante ao fenômeno do sickness behavior apresentado por animais de laboratório, em humanos, quadros de fadiga, dor, insônia, depressão e distúrbios cognitivos também foram observados em 
pacientes com câncer, os quais exibiram altos níveis de expressáo de citocinas pró-inflamatórias. ${ }^{(2,6,7)} \mathrm{A}$ instalação do quadro de sickness behavior em pacientes oncológicos culminou na evoluçáo de um novo conceito - o de "cluster de sintomas neuropsicológicos" - que é definido como um conjunto de sintomas emocionais ou comportamentais que pode estar relacionado com a disfunção psicológica ou neurológica e que tendem a ocorrer em pacientes com câncer. ${ }^{(7)}$

Existe uma consciência crescente de que mecanismos biológicos comuns podem estar subjacentes à interação entre os sistemas nervoso, endócrino e imune, os quais orquestram um conjunto de respostas capazes de instalar mudanças comportamentais e fisiológicas no organismo animal e humano. (6) Particularmente, estudos que abrangem o sickness behavior, bem como os clusters de sintomas neuropsicológicos em pacientes com câncer suportam a hipótese de que citocinas pró-inflamatórias estáo relacionadas aos mecanismos biológicos subjacentes ao surgimento desses agrupamentos sintomatológicos. ${ }^{(2,6,7)}$ A liberação de citocinas, tais como IL-1 $\beta$, IL-6, IL-8, IL-10, IL-12p70, TNF- $\alpha$ e IFN-y, por exemplo, resulta em sintomas neuropsicológicos, incluindo humor deprimido, fadiga, depressão, distúrbios do sono e aumento da sensibilidade à dor. Alteraçóes em citocinas e outros processos psiconeuroimunológicos podem ser críticas para a produção de sintomas e, potencialmente, para a prevenção e tratamento dos mesmos. ${ }^{(2,6,7)}$ Nesse sentido, a PNI apoia a ideia de que as cascatas de comunicação imune-cerebral podem estar relacionadas ao desenvolvimento de inúmeras patologias, bem como ao surgimento dos clusters de sintomas desagradáveis relacionados ao seu tratamento, mediados por diversos processos inflamatórios e neuroimunoendócrinos. ${ }^{(2,6)}$

Pesquisas acerca da PNI realizadas pela enfermagem eram relativamente limitadas no passado. No Brasil, um dos primeiros estudos na temática avaliou os efeitos da intervenção de enfermagem-relaxamento nas células com atividade natural killer em mulheres com câncer de mama. ${ }^{(8)}$ Contudo, esse tema de pesquisa está se tornando cada vez mais comum à medida que enfermeiros completam seu grau acadêmico adicional nas ciências básicas, lhe desenvolvem e integram em equipes de pesquisadores das áreas básicas, bem como à medida em que se tornam mais conscientes das projeçóes da ciência da PNI. ${ }^{(9,10)} \mathrm{O}$ resultado dessas colaboraçôes, há um crescimento sinérgico na investigaçáo translacional e interdisciplinar focada na fusão das dimensões biológicas, psicológicas e socioculturais da assistência ao paciente, com vistas a melhorar os desfechos em saúde dos mesmos. ${ }^{(10)}$

Os resultados de investigaçóes científicas desenvolvidas por enfermeiros, à luz das ciências básicas, são balizadores do cuidado personalizado. Essas investigaçóes contribuem com a percepção das complexas interaçôes e variaçôes que ocorrem nos sistemas biológicos, que estão intrinsecamente relacionadas ao cuidado diário provido aos pacientes. ${ }^{(9,10)}$ Sintomas desagradáveis, tais como dor, fadiga, ansiedade e alteraçôes nos padróes de sono, dentre outros, são relatados diariamente na prática clínica aos profissionais de enfermagem, os quais devem ser encorajados a se aproximar das ciências 
básicas a fim de compreender como o manejo e o cuidado clínico podem ser influenciados pelas descobertas realizadas nas bancadas dos laboratórios. Assim, é importante que o enfermeiro participe e identifique estratégias para acelerar a investigação translacional a partir do cenário de prática profissional a fim de auxiliar na compreensão dos mecanismos fisiopatológicos subjacentes associados a esses sintomas, visando intervir efetivamente. ${ }^{(10)}$

O profissional enfermeiro encontra-se em uma posição ideal para desenvolver intervençôes personalizadas, pois, notoriamente, são os profissionais que estão na linha de frente do cuidado, prestando assistência ininterrupta aos pacientes. Ademais, enfermeiros são reivindicados para desempenhar um atendimento integral ao paciente, utilizando-se a melhor evidência da literatura científica, tanto para manejo dos clusters de sintomas neuropsicológicos, quanto para engajar-se em um ciclo contínuo de atualizações e novas aplicaçóes na prática clínica visando intervençóes personalizadas ao paciente. É importante considerar o processo de educação permanente para o profissional de enfermagem de modo a capacitá-lo para as novas demandas provenientes da PNI, por exemplo, frente às novas tecnologias e informações genômicas disponíveis, a compreensão e interpretação de resultados dos testes de biomarcadores em relação à eficácia de uma variedade de intervençôes farmacológicas e não farmacológicas para manejo dos clusters de sintomas neuropsicológicos e a administração de terapias-alvo com base na constituição genética de cada paciente (farmacogenômica). ${ }^{(10)}$ Contudo, sempre tendo em vista o padrão holístico e centrado no paciente e na família, de modo a integrar os novos conhecimentos ao processo de enfermagem.

Esses aspectos ratificam e apoiam a Prática Baseada em Evidências (PBE), honrando a autonomia científica dos cuidados prestados por esses profissionais, dando subsídios para uma assistência qualificada. A pesquisa científica é o grande propulsor da PBE, pois, por meio de descobertas científicas, intervenções bem sucedidas têm sido incorporadas com segurança à prática clínica. Entretanto, tanto a PNI como a PBE, ainda ocorrem de modo bastante incipiente no universo da enfermagem brasileira. Encoraja-se o desenvolvimento de pesquisas por enfermeiros que objetivem incorporar e implementar o uso seguro de novas práticas e procedimentos com vias às açôes de prevenção, promoçãa e recuperação da saúde. A aplicação das descobertas e dos resultados das pesquisas realizadas por enfermeiros alavancam a cientificidade e a autonomia do cuidado prestado pelo enfermeiro ao cliente e à sua família.

Pesquisas na área de PNI têm o potencial de validar aspectos do cuidado que os enfermeiros exercem intuitivamente em benefício dos pacientes, além de, por exemplo, subsidiar a implementaçáo do uso de terapias complementares na prática de enfermagem com respaldo científico. ${ }^{(1-14)}$

Um dos principais objetivos da pesquisa do PNI é determinar se existe uma associação válida entre fatores de risco e os desfechos imunológicos. Se, por um lado, os métodos usados nesse tipo de avaliação não estáo disponíveis com facilidade para enfermeiros pesquisadores, que geralmente estão realizando pesquisas com restrições de recursos, por outro lado, os enfermeiros 
usam parâmetros muito amplos que consideram as mudanças fisiológicas dentro de um contexto psicossocial complexo. Assim, pesquisas para avaliar o valor de intervençóes de enfermagem, se projetados com uma perspectiva integral da PNI, permitirão que os pesquisadores enfermeiros avaliem o que tais profissionais afirmam levar em consideração intuitivamente, bem como quais processos biológicos e comportamentais estão intimamente entrelaçados e precisam ser considerados na prestação de cuidados ao paciente, de modo a auxiliá-los com qualidade e segurança em sua jornada no processo saúde-doença-cuidado. ${ }^{(9)}$

Atualmente, uma das temáticas mais desafiadoras para os enfermeiros, seja em ambientes de pesquisa ou da prática clínica, é o manejo dos clusters de sintomas neuropscicológicos relacionados as diversas patologias. ${ }^{(2,15)} \mathrm{Em}$ geral, as pesquisas em oncologia estão, em sua maioria, concentradas no estudo da prevalência e do tratamento de sintomas isolados, em vez de considerá-los de modo aglomerado. Entretanto, sabe-se que, na prática clíni$\mathrm{ca}$, os sintomas raramente ocorrem separadamente. Eles podem se agrupar, criando um efeito sinérgico que leva a um aumento da sua intensidade ou a um efeito antecessor, que pode predizer o desenvolvimento de sintomas futuros. ${ }^{(2,7,15)}$

Enfermeiros pesquisadores devem estar cientes e sensibilizados à experiência dos pacientes em relação a esses sintomas desagradáveis. O estudo dos mesmos gera oportunidades ricas de pesquisa, como, por exemplo: a) a trajetória, o desenvolvimento e a gravidade desses sintomas ao longo do tempo (tratamento e pós-tratamento); b) as inter-relaçóes entre esses sintomas por faixa etária, por aspectos socioculturais e espirituais, por diagnóstico e por fase do tratamento; e c) como ocorre a formação dos agrupamentos entre eles. Há também um grande potencial para o avanço da enfermagem por meio de pesquisas que avaliem as vias psiconeuroimunoendócrinas envolvidas na gênese desses clusters de sintomas.

Tais pesquisas poderão fornecer uma base para o desenvolvimento de futuras intervençóes. Ressalta-se que o manejo desses sintomas é uma questão importante e um aspecto vital da prática de enfermagem, dado o seu papel importante desempenhado na avaliação clínica, na monitorização dos sintomas e dos efeitos colaterais da terapêutica. Até que estudos mais definitivos de agrupamentos de sintomas sejam realizados, os enfermeiros precisam acompanhar os pacientes para a co-ocorrência de múltiplos sintomas e desenvolver planos de cuidados personalizados, utilizando-se da PNI em consonância com o cuidado para transpor a PBE.

Devido à ligação aparente entre esses sintomas e mecanismos biológicos, estudos que se destinem a melhor compreender os possíveis mecanismos biomoleculares constituem uma importante área de pesquisa. No contexto da enfermagem, pesquisas que garantam a melhor compreensão da etiologia e dos mecanismos psicossociais e biológicos de clusters de sintomas desagradáveis permitirão que as intervençôes realizadas por enfermeiros sejam propostas com maiores subsídios científicos. Uma vez identificada a associação ou o grau de sensibilidade e especificidade de biomarcadores, os mesmos 
poderão ser utilizados em resposta a intervençóes de enfermagem, para que seja possível determinar com acurácia a eficácia das mesmas. Em outras palavras, para quem e em que contexto as intervençóes funcionarão (qual a dose, o tipo, com que frequência), quando deverão ser empregadas (antes, durante ou após o tratamento), e por quanto tempo (duração). ${ }^{(10,16)}$

As recentes abordagens da PNI têm mostrado um vasto campo de análises para a compreensão das conexôes entre os diversos sistemas e as alteraçóes biocomportamentais em pacientes em diferentes contextos. Tais conexôes não devem ser desprezadas ou subestimadas em qualquer área da pesquisa biomédica, pois podem ser responsáveis por fenômenos ainda pouco compreendidos. A integração de modelos biológicos e psicológicos vem se tornando cada vez mais importante no processo saúde-doença-cuidado. Ademais, as intervençóes terapêuticas cujos alvos são o eixo neuroimunoendócrino são promissoras para o cuidado personalizado em saúde, por sua capacidade de interferir na fisiologia dos sistemas nervoso e endócrino e modular a resposta imune.

A compreensão de como as vias neuroimunoendócrinas regulam o desenvolvimento da doença, bem como dos aspectos subjacentes às terapêuticas específicas, como a imunoterapia, constitui-se em fronteira importante para futuras investigações. Tal compreensão pode contribuir na elucidação do diagnóstico e do prognóstico de diversas patologias e até mesmo auxiliar na seleção de terapias personalizadas mais bem indicadas para cada paciente ou para cada tipo de doença. Finalmente, salienta-se que o campo da PNI envolve, para além de questôes científicas, assuntos financeiros, éticos, legislativos, bem como reguladores e operacionais, os quais se transpóem como desafios importantes para pesquisadores translacionais, a fim de otimizar, tornar viável e bem-sucedido o processo de translação. Apesar de esta ser uma proposta desafiadora para a enfermagem, o caminho da investigaçáo de translação pode fornecer benefícios para os indivíduos e as suas famílias, especialmente como uma promessa potente de melhoria da sua qualidade de vida.

Maria Helena Costa Amorim Professora Titular Visitante da Escola Paulista de Enfermagem, Universidade Federal de São Paulo, São Paulo, SP, Brasil. https://orcid.org/0000-0002-4252-7092

Luís Carlos Lopes-Júnior Professor Adjunto do Departamento de Enfermagem, Universidade de Federal do Espírito Santo, Vitória, ES, Brasil. https://orcid.org/0000-0002-2424-6510

Como citar:

Amorim MH, Lopes-Júnior LC. Psiconeuroimunologia e a pesquisa em enfermagem: descoberta, mudanças de paradigma e inovaçōes metodológicas. Acta Paul Enferm. 
DOI: http://dx.doi.org/10.37689/acta-ape/2021EDT1.

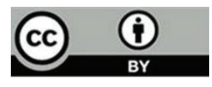

\section{Referências}

1. Ader R. On the development of psychoneuroimmunology. Eur J Pharmacol. 2000;405(1-3):167-76.

2. McDonald GP, O'Connell M, Lutgendorf SK. Psychoneuroimmunology and cancer: a decade of discovery, paradigm shifts, and methodological innovations. Brain Behav Immun. 2013;30 Suppl:S1-9.

3. Dantzer R, O'Connor JC, Freund GG, Johnson RW, Kelley KW. From inflammation to sickness and depression: when the immune system subjugates the brain. Nat Rev Neurosci. 2008;9(1):46-56.

4. Kent S, Bluthé RM, Kelley KW, Dantzer R. Sickness behavior as a new target for drug development. Trends Pharmacol Sci. 1992;13(1):24-8.

5. Renault J, Gheusi G, Aubert A. Changes in social exploration of a lipopolysaccharides-treated conspecific in mice: role of environmental cues. Brain Behav Immun. 2008;22(8):1201-7.

6. Dantzer R, Kelley KW. Twenty years of research on cytokine-induced sickness behavior. Brain Behav Immun. 2007;21(2):153-60.

7. Kim HJ, Barsevick AM, Fang CY, Miaskowski C. Common biological pathways underlying the psychoneurological symptom cluster in cancer patients. Cancer Nurs. 2012;35(6):E1-20.

8. Amorim MH, Rumjanek V. 0 efeito da intervenção de Enfermagem relaxamento nas células com atividade natural killer em mulheres com câncer de mama. In: VI Colóquio Pan-Americano de Investigação em Enfermagem. Anais... Ribeirão Preto: 1998; p.344.

9. Langley P, Fonseca J, Iphofen R. Psychoneuroimmunology and health from a nursing perspective. Br J Nurs. 2006;15(20):1126-9.

10. Lopes-Júnior LC, Olson K, de Omena Bomfim E, Pereira-da-Silva G, Nascimento LC, de Lima RA. Translational research and symptom management in oncology nursing. Br J Nurs. 2016;25(10):S12, S14, S16 passim.

11. Primo CC, Amorim MH, Leite FM. A intervenção de Enfermagem-Relaxamento e seus efeitos no sistema imunológico de puérperas. Acta Paul Enferm. 2011;24(6):751-5.

12. Silva HL, Almeida MV, Diniz JS, Leite FM, Moura MA, Bringuente ME, et al. Efeitos da auriculoterapia na ansiedade de gestantes no pré-natal de baixo risco. Acta Paul Enferm 2020;33:eAPE20190016.

13. Olympio PC, Lima E, Amorim MHC. Mulher mastectomizada: Intervenções de Enfermagem e atividade natural killer. Rev Epidemiol Control Infect. 2014;4(1):7-11.

14. Araújo WS, Romero WG, Zandonade E, Amorim MH. Effects of relaxation on depression levels in women with high-risk pregnancies: a randomised clinical trial. Rev Lat Am Enfermagem. 2016;24(0):e2806.

15. Dodd MJ, Miaskowski C, Lee KA. Occurrence of symptom clusters. J Natl Cancer Inst Monogr. 2004;2004(32):76-8.

16. Berger AM, Yennu S, Million R. Update on interventions focused on symptom clusters: what has been tried and what have we learned? Curr Opin Support Palliat Care. 2013;7(1):60-6. 